\title{
CONTEXTUALIZANDO AS ÁREAS VERDES URBANAS: UM ESTUDO DAS PRAÇAS EM CANHOTINHO/PE
}

\section{Elaynne Mirele Sabino de França ${ }^{1}$}

Maria Betânia Moreira Amador ${ }^{2}$

RESUMO: O presente trabalho traz algumas discussões e definições, aproximadas, em relação a inquietações referentes as inúmeras conceituações de uma área verde urbana, espaço público e de como as praças desempenham função ecológica-social no ambiente urbano. Numa tentativa de realizar esta reflexão, toma-se como referencia para categorizar as áreas verdes Benini e Martin que propõem, ao citar Daltoé, Cattoni, Loch, diante do que pode ser observado e dos elementos que fazem parte destas paisagens, no que diz respeito a um problema na conceituação e utilização de termos relativos ao objeto de estudo. E, no caso especifico dessa pesquisa, procurou-se aplicar esta classificação tomando-se por base duas das principais praças do município em estudo.

Palavras-chave: Áreas verdes urbanas, classificação, praças.

${ }^{1}$ Licencianda do Curso de Geografia. UPE, Campus Garanhuns. elaynnemirelle@hotmail.com

2Doutora em Geografia, Professora Adjunta do Curso de Licenciatura em Geografia. UPE, Campus Garanhuns. betaniaamador@yahoo.com.br 


\section{INTRODUÇÃO}

A geografia pouco tem explorado as discussões sobre os espaços públicos urbanos com um olhar interdisciplinar e sistêmico em seus principais autores do pensamento geográfico, mas observa-se que algumas iniciativas veiculadas em eventos científicos da área estão trazendo para discussão a questão dos espaços urbanos na cidade atual sob esta ótica.

Então, com base na literatura consultada sobre o tema em tela, foi constituída uma tabela na qual pode-se ver pelas figuras dispostas, uma representação do que seria diferentes tipos de áreas verdes presentes na cidade. Apresentando-se um das possíveis abordagens deste processo de diferenciação em aplicação as principais praças de Canhotinho/PE.

Procura-se esclarecer e proporcionar uma visão mais integradora, a partir das proposições de alguns autores, numa tomada de consciência em que o homem possa perceber as praças de maneira mais ampla de forma que seja possível somar o conhecimento denominado senso comum ao conhecimento cientifico. Em sua maioria, a sociedade conceitua a praça como um lugar sem sentido ou com relevância para cidade, ou seja, nem sempre essa sociedade se apercebe do valor da praça e todos seus equipamentos arquitetônicos, paisagísticos e/ou recreativos, muito menos dos espécimes verdes para o ambiente.

Considerando-se, assim, a arborização como tabua de salvação ou, ainda melhor, como fator amenizador da desordem e instabilidades que o homem tem provocado com suas ações mal planejadas na constituição das cidades, pela vegetação arbórea presente nas praças consideradas "espaços livres públicos" , logo cabe considerar que a paisagem urbana tem nos elementos verdes, sejam arbóreos ou não, um de seus alicerces de bem estar, conforto e beleza.

\section{DENVOLVIMENTO}


O homem em sua busca constante por qualidade de vida visa se adaptar em lugares propícios a manutenção desse imperativo e, no caso, as cidades foram escolhidas como ambientes satisfatórios na busca desse fim.

Pelo que pode ser observado, os ambientes urbanos proporcionam melhor infraestrutura, e naquelas que realmente possuem passa a tornar-se fundamental para manter uma vida saudável. Diante desse contexto, o processo de urbanização motivado por períodos históricos diferentes mas, principalmente pela Revolução Industrial do século XVIII, faz com que haja um (des)enfreado e (des)ordenado processo de urbanização, no qual o crescimento econômico era mais importante sem preocupação com a questão ecológica e social.

Inicialmente, a cidade como resultado desse processo de urbanização era tida como uma negação da natureza presente em suas mediações, ela vem a ser uma nova roupagem dos ambientes em que se faz a retirada do verde para ceder lugar a outra forma, se configurando assim numa oposição (HENRIQUE, 2009).

No entanto, cabe considerar que as pessoas acorriam às cidades às centenas, e essas áreas careciam do mínimo de planejamento para atender essa demanda. 0 crescimento urbano associado a degradação do ambiente entra em grande discussão quando afeta a qualidade de vida da população. Considerando-se alguns eventos mundiais e tendo-se como objetivo debater os impactos das atividades humanas nos ambientes destaca-se a Agenda 21, a qual indica que discussões devem ser realizadas quanto a preocupação de se fazer estudos que tratem das estimativas de crescimento populacional e de como isso vem provocar alterações no ambiente.

A natureza ou, mais precisamente, o verde presente na área urbana passa a ser introduzida na cidade concretizando-se em jardins e praças (HENRIQUE, 2009). Para tal, sua contribuição para estes lugares em termos ambientais vem através de um percentual mínimo de vegetação buscando, de forma intrínseca, amenizar os impactos provocados pela ação humana. 
Ao falar do verde no sistema urbano adota-se uma visão integradora, ou seja, sistêmica das relações que se estabelecem na dinâmica da paisagem. Para compreender os ambientes que contêm vestígios do verde, entendida como representação da natureza na cidade, pode-se segundo Amador (2011), ter-se a perspectiva sistêmica como método analítico da natureza considerando-se os fenômenos em suas interações sem fazer uma redução dos elementos em si.

Para tecer este estudo e enfocando ainda mais a linha que se segue, toma-se Tricart (1979, p. 79) que diz: " [..] Estudar a organização do espaço é determinar como uma ação se insere na dinâmica natural, para corrigir certos aspectos desfavoráveis [...]". Mostra-se, assim, como forma apropriada considerando-se o que foi destacado. Tomando-se, ainda, este pensamento como referencia, outro autor que segue a mesma linha sistêmica afirma que,

É, em uma determinada porção do espaço, o resultado da combinação dinâmica, portanto instável, de elementos físicos, biológicos e antrópicos que, reagindo dialeticamente uns sobre os outros, fazem da paisagem um conjunto único e indissociável, em perpétua evolução. A dialética tipo-indivíduo é próprio fundamento do método de pesquisa. (BERTRAND, 2004, p.141)

Esse autor enfoca, mais uma vez, a perspectiva da lógica do sistema a ser considerada quando se pensa os diferentes elementos dispostos sobre a superfície terrestre - atmosfera, vegetação e o homem - em que estes ainda possuem uma interdependência explícita ao dialogarem entre si em seus diversos processos.

É de se considerar que as atuais discussões ambientais e, em especial, as relacionadas ao verde - tanto urbano, quanto rural - estão cada vez mais presentes no seio da sociedade. Diante disso faz-se necessário entender o real significado de uma área verde, que representa a natureza plantada ou não no espaço geográfico e para isso expõe-se o seguinte conceito: 
Área verde: Onde há o predomínio de vegetação arbórea, englobando as praças, os jardins públicos e os parques urbanos. Os canteiros centrais de avenidas e os trevos e rotatórias de vias públicas que exercem apenas funções estéticas e ecológicas, devem, também, conceituar-se como área verde. Entretanto, as árvores que acompanham o leito das vias públicas não devem ser consideradas como tal, pois as calçadas são impermeabilizadas (LODOBA e ANGELIS, 2005, p. 133)

Neste momento, adota-se um critério que define se aquele conjunto de árvores distribuídas pela cidade pode ser ou não uma área verde, quando se diz que o lugar que tiver um elemento vegetal não poderá ser considerado como área verde, pois o lugar encontra-se impermeabilizado.

Entretanto, ressaltando-se as palavras de Santos (2002, p.1): "todo o complexo arbóreo de uma cidade, quer seja plantado ou natural, compõe em termos globais a sua área verde", todas as árvores constituintes dos/nos espaços urbanos são assim entendidas.

Entretanto, as árvores presentes nas vias públicas não podem ser consideradas neste contexto, por fazer parte da composição simples estética, com finalidades distintas, sua área pouco impermeável enquanto as áreas verdes têm com funções principais a recreação e lazer (SANTOS 2002, p.1).

Perante o fato de se observar vários espaços que contem o verde em CanhotinhoPE (Quadro 1 ), destacando-se então a importância de se realizar uma classificação das áreas verdes dispostas nos sistema urbanos com a finalidade de diferenciar, organizar e, também, esclarecer quem são os responsáveis por manter estas áreas. Os autores Daltoé, Cattoni, Loch apud Benini (2011) sugerem uma categorização das áreas verdes, determinadas em seis classes: Áreas verdes do sistema viário; Áreas verdes de uso particular; Áreas verdes públicas e/ou de uso coletivo; Áreas livres não arborizadas (vazios urbanos), (organização nossa). 


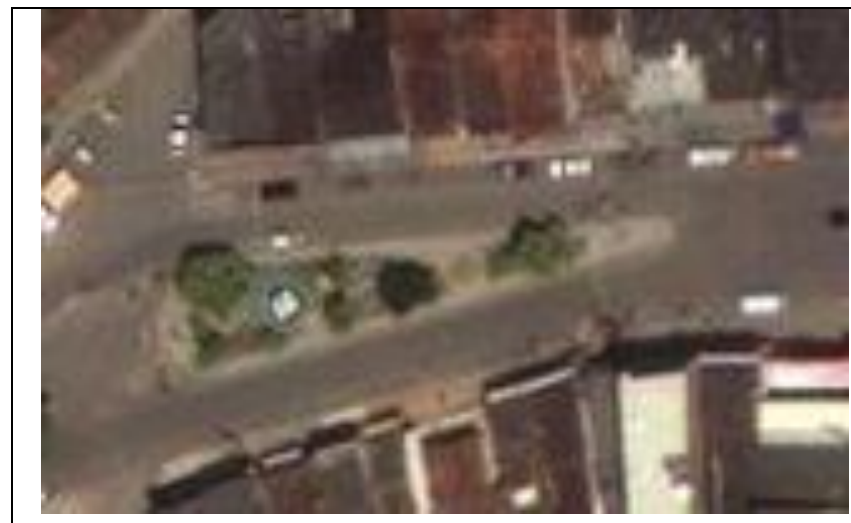

Figura 1: Praça Padre Josias Ferreira de Paula.

Categoria: Áreas verdes públicas e/ou de uso coletivo.

Características: apresenta árvores,

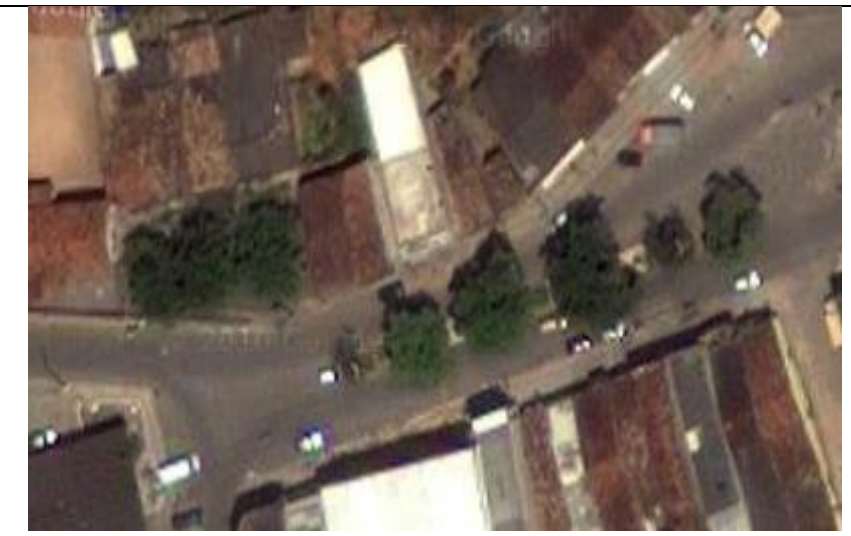

Figura 2: Imagem de Canteiro Central.

Categoria: Áreas verdes do sistema viário.

Características: considerando os canteiros, trevos e rotatórias que possuem cobertura vegetal.

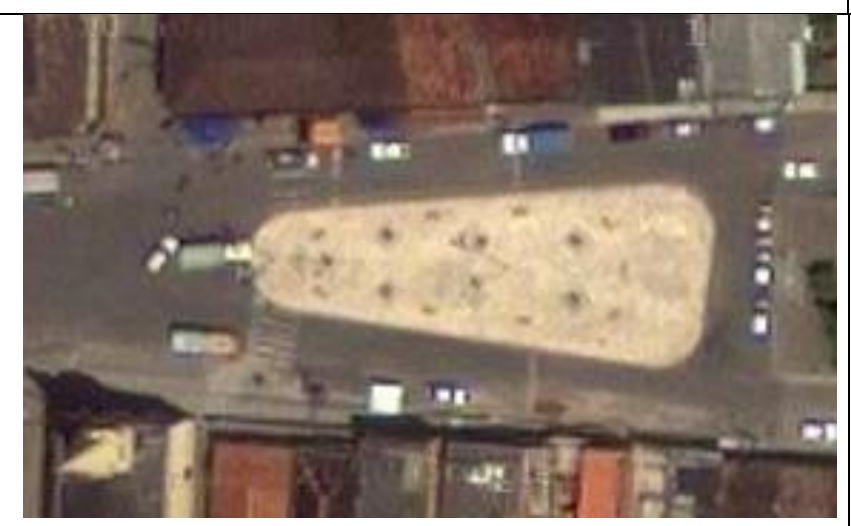

Figura 3: Praça Padre Callou de Alencar.

Categoria: Áreas livres não arborizadas (vazios urbanos).

Características: aquelas que não apresentam cobertura arbórea.

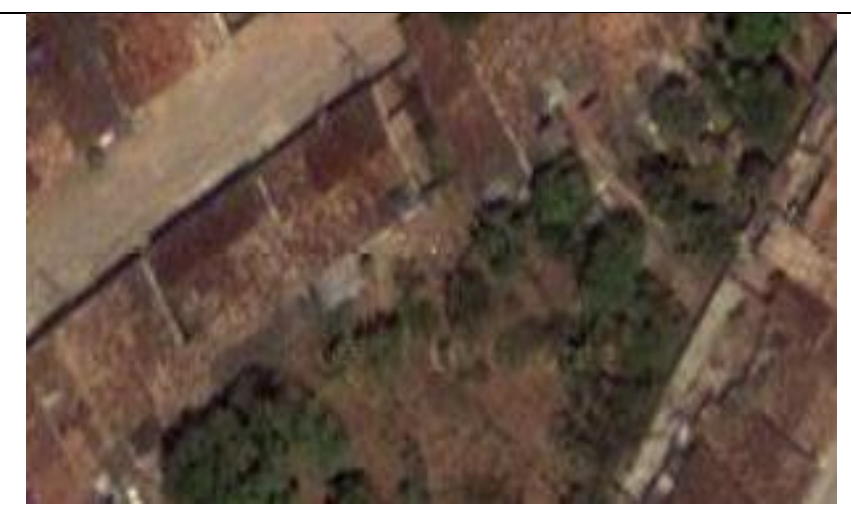

Figura 4: Imagem de quintais privados.

Categoria: Áreas verdes de uso particular.

Características: representadas pelas chácaras e ambientes de uso estrito, composta por árvores. 


\section{Quadro 1:}

Figuras representativas da classificação das áreas verdes de Canhotinho - PE, 2013

Ressaltando-se pois, a área verde pública e/ou de uso coletivo que engloba o ponto alto do trabalho, ou seja, a praça determinada como:

Nesse grupo enquadram-se as áreas verdes de composição mista com arborização significativa (espécies exóticas e nativas). Compreendem as praças, parques e bosques urbanos, assim como áreas arborizadas dentro dos complexos históricos. Possuem alto valor ecológico, cênico e social. (DALTOÉ; CATTONI; LOCH, 2004, p. 3-4 apud Benini ; Martin, 2002).

Ainda segundo BENINI e MARTIN (2012, p. 77):

Área verde pública é todo espaço livre (área verde/lazer) que foi afetado como de uso comum e que apresente algum tipo de vegetação (espontânea ou plantada), que possa contribuir em termos ambientais (fotossíntese, evapotranspiração, sombreamento, permeabilidade, conservação da biodiversidade e mitigue os efeitos da poluição sonora e atmosférica) e que também seja utilizado com objetivos sociais, ecológicos, científicos ou culturais.

Entende-se, pois que as praças estão caracterizadas como uma área verde pública, um espaço livre a disposição de todos, com árvores (natural ou artificial) ou não, permeável realizando as funções especificas gerada pela vegetação arbórea e também lugar de manifestação social (monumentos, festa tradicionais, prédios públicos). Destacase, também, a posição de GOMES (2012) em relação a esse assunto:

Espaços livres correspondem a espaços urbanos ao ar livre, destinados à utilização que se relacione com caminhada, descanso, passeio, práticas de esporte, recreação e entretenimento. Podem ser privados, potencialmente coletivos ou públicos e podem desempenhar, principalmente, funções estéticas, de lazer e ecológica ambiental, entre outras. CAVALHEIRO et al. 1999 apud GOMES (2012, p. 749). 
Considerando o espaço público a partir da "análise da acessibilidade", sua apropriação pela sociedade ultrapassa as dimensões físicas e pode-se falar numa apropriação simbólica destes lugares, pois o que é público nos remete a ser disponibilizado, via regra, para todos sem distinção dos homens sem a menor distinção social, econômica e cultural e de outra forma que não se fixe apenas neste acesso concreto dos "espaços "abertos" de uso coletivo" (SERPA, 2009, p.16).

De acordo com Benini (2011) o objetivo principal desempenhado por uma praça é o lazer e determinando-a ainda como um espaço livre público, em que se pode ou não encontrar vestígios arbóreos, onde se depara com área para infiltração das águas pluviais ou da ação humana ao jorrar água na vegetação.

Então, em especial as praças que contém vegetação são tidas como importantes "espaços livres públicos" de manifestação do verde em sua maioria, principalmente das cidades interioranas - ressaltando que em muitos casos não possuem espaço e planejamento adequado ou interesse para introdução de parques, jardins botânicos, entre outros - com função primordial de balancear os efeitos provocados principalmente pela ação antrópica na dinâmica local a partir da vegetação arbórea quando esta possibilita a absorção de gases, controle de temperatura, fornecimento de alimento e habitat para alguns animais da micro e/ou mesofauna, além de outras benesses.

Nesta perspectiva o homem vê nas praças uma tabua de salvação, ou ainda melhor, como fator amenizador da desordem e instabilidades que tem provocado com suas ações mal planejadas, ou seja, uma possibilidade de atenuar o caos está na (re)constituição de áreas verdes naturais e artificiais como parques, praças, jardins em meio às cidades, mesmo que de pequeno e/ou médio porte.

Todos devem estar cientes que as árvores contidas nos parques, praças, jardins não irão resolver os problemas ambientais climáticos, paisagísticos, de ordenação espacial dentre outros provenientes das implicações provocadas pela ação do homem ao transformar e fazer uso da natureza, se considera pois, ser uma tentativa de amenizar as dificuldades que as áreas urbanizadas enfrentam. 
Enfatizando-se as praças compostas por vegetação desde arbustos até árvores de grande porte, cujo elemento vegetal é formado por raiz, caule e copa que, por sua vez, contem ramos, flor, fruto e que envolve no seu metabolismo os seguintes procedimentos:

Fotossíntese - processo em que o gás carbono disposto na atmosfera vai ser absorvido pela planta conjuntamente com água e minerais do solo e transformado em oxigênio e composto orgânico.

Respiração - método em que se vai conseguir energia a se manter, proveniente da necessidade de oxigênio para que ocorra a conversão dos compostos orgânicos estocados.

Transpiração - é um processo de evaporação da água contida no interior do vegetal a partir eliminação, que ocorre para estabilizar a temperatura da planta por suas folhas.

Absorção e Translocação - diz-se do movimento que acontece no seu interior, ao extrair água e nutrientes do solo pelas raízes e posterior a eliminação de $\mathrm{H}_{2} \mathrm{O}$ provoca a circulação das substâncias.

O produto de toda movimentação são apresentados ao equilíbrio que as árvores proporcionam no meio como: absorção de gases presentes na atmosfera e que atenua a velocidade e resquícios de poeiras presentes nos ventos, influencia na temperatura, contribui na infiltração de águas favorecendo o controle do volume de águas em período de intensas chuvas e diminui a velocidade dos pingos. Também fica evidente a redução dos efeitos sonoros provocados pelos transportes e estabelecimentos próximos, ameniza a luminosidade dos raios solares e fornecimento de alimento e habitat para a fauna, visual estético e fragrância agradável, entre outros.

Contudo, o verde precisa de cuidados para realizar suas funções nos ambientes. Em relação aos "espaços livres públicos" é primordial um planejamento adequado para a instalação ou revitalização de uma praça. Em termos de plantios de árvores enfatiza-se que seja feito por um profissional capacitado, pois grandes problemas podem futuramente ocorrer. As espécies arbóreas possuem características inerentes de cada vegetal, como: 
- Tamanho e expressividade que pode atingir em sua idade adulta - podendo influenciar diretamente na circulação dos frequentadores.

- Se frutífera - podem danificar outros elementos componentes da praça e provocar acidentes as pessoas que transitam e convivem nesse lugar.

- Fragrância dispersada pelas flores - se são agradáveis ou não.

- Condições físicas da planta - se esta em bom estado de saúde, suas raiz estão saudáveis ou não o que ocasionaria uma queda do vegetal.

Julga-se ser necessário lançar, ainda, um olhar atento ao tipo de espécies animais que provavelmente frequentariam estes espaços e como se daria a relação deles com o ambiente. São algumas das possibilidades que devem ser consideradas antes de se implantar uma área arborizada e principalmente no sistema urbano, ponderando ainda outros aparelhamentos urbanos, redes de distribuição elétricas, as tubulações de esgoto, canais de água, calçamento ou asfalto, prédios públicos e privados próximos, são alguns equipamentos possíveis a serem danificados pela vegetação.

As influencias e danos gerados pela ação antrópica são manifestadas nesses ambientes natural ou artificial, quanto ao uso e função dada as praças, em sua relação e preservação com os artefatos distribuídos e a utilidade diante da visibilidade do número de pessoas que transitam e comercializam produtos, em sua maioria alimentícios.

Diante da reflexão e contextualização desses pressupostos e reflexão sobre a definição aproximada de praça realizada por alguns autores buscados na literatura, discorre-se sobre o objeto de estudo, ou seja, a Praça Padre Josias Ferreira de Paula localizada no município de Canhotinho - PE.

\section{LOCALIZAÇÃO DO MUNICÍPIO EM ESTUDO}

O município apresenta área total de $423,0 \mathrm{~km}^{2}$ com densidade demográfica de 57,25 hab./km² e localiza-se Mesorregião do Agreste, Microrregião de Garanhuns. Limitase ao norte com Lajedo e Jurema, ao sul com Palmeirina, a leste com Quipapá e o estado de Alagoas, a oeste com Calçado e Angelim (Mapa 1). 
Canhotinho pode ser considerada um dos exemplos, entre as cidades interioranas de pequeno porte. Possui uma população que guarda em sua cultura, valores que são passados de pai para filho sendo, portanto, de grande importância a identidade com este território, um sentimento muito explicito de pertencimento do lugar e das pessoas que outrora, também habitaram esta cidade.

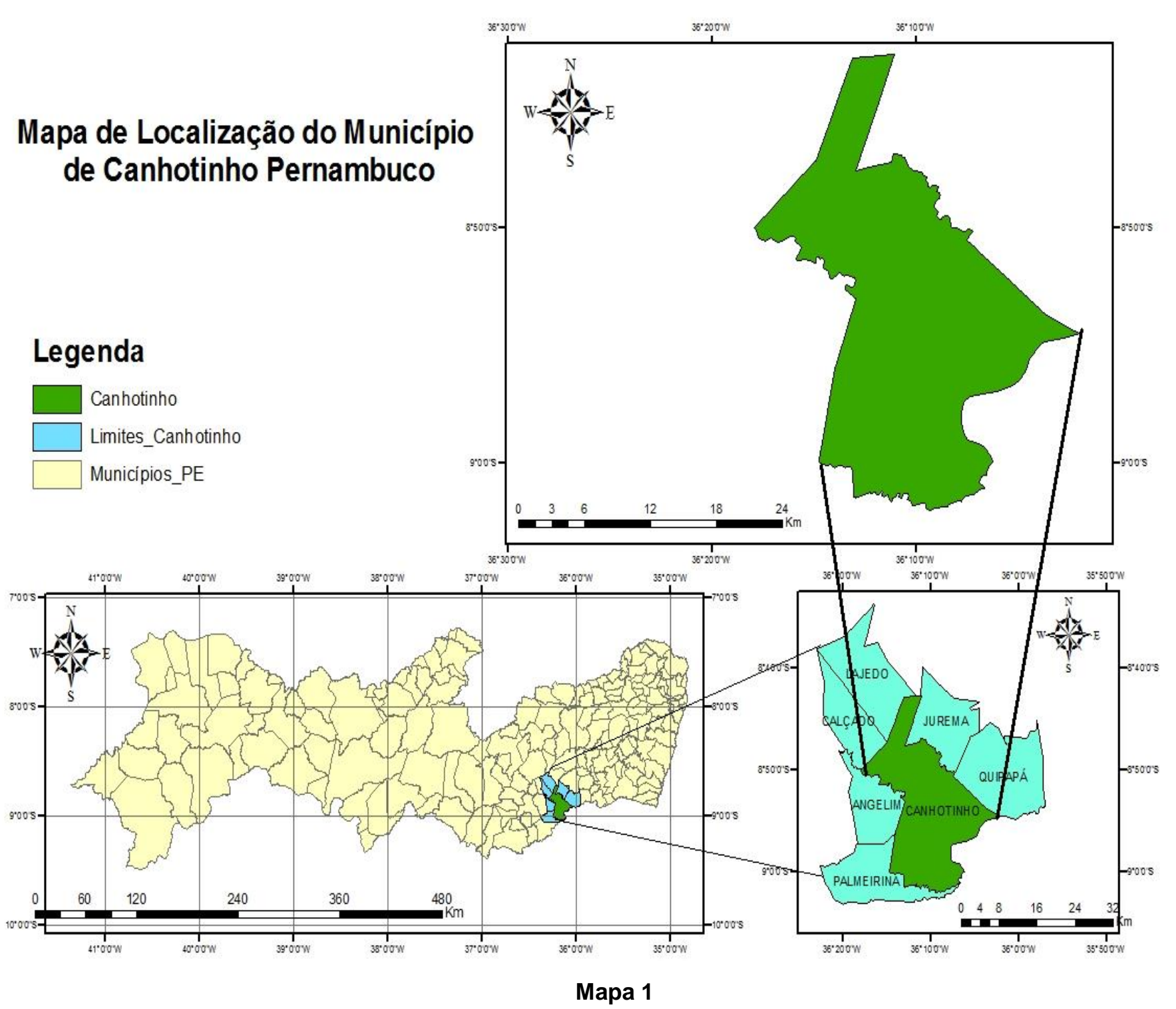

Mapa de Localização do Município de Canhotinho Pernambuco, adaptado por FRANÇA, E.M.S.

Tendo-se tratado sobre o município de Canhotinho, apresenta-se a praça selecionada para o referido trabalho. A mesma chama-se Praça Padre Josias Ferreira de Paula. 


\section{PRAÇA PADRE JOSIAS FERREIRA DE PAULA}

Seu nome é uma homenagem ao Padre Josias Ferreira de Paula (1964-1982), o qual por alguns anos esteve a frente da paróquia de Nossa Senhora da Conceição. A praça (Figura 6), foi construída no ano de 1988 em tributo ao ilustre padre e amigo dos cidadãos canhotinhenses pela sua postura amável e bondade para com todos.

Localizada na parte central e comercial da referida cidade, ou seja, na Rua Eugênio Tavares de Miranda, área de grande valorização espacial pelos comerciantes de bens duráveis e não duráveis, onde a concorrência e o valor de alugueis dos recintos são bem avaliados em relação às outras localidades. Área em que quase não se encontra casas domiciliares, já produto da ação do homem que a partir das suas relações sociais, está empurrando as residências para as regiões periféricas das cidades e, as casas comerciais para os centros.

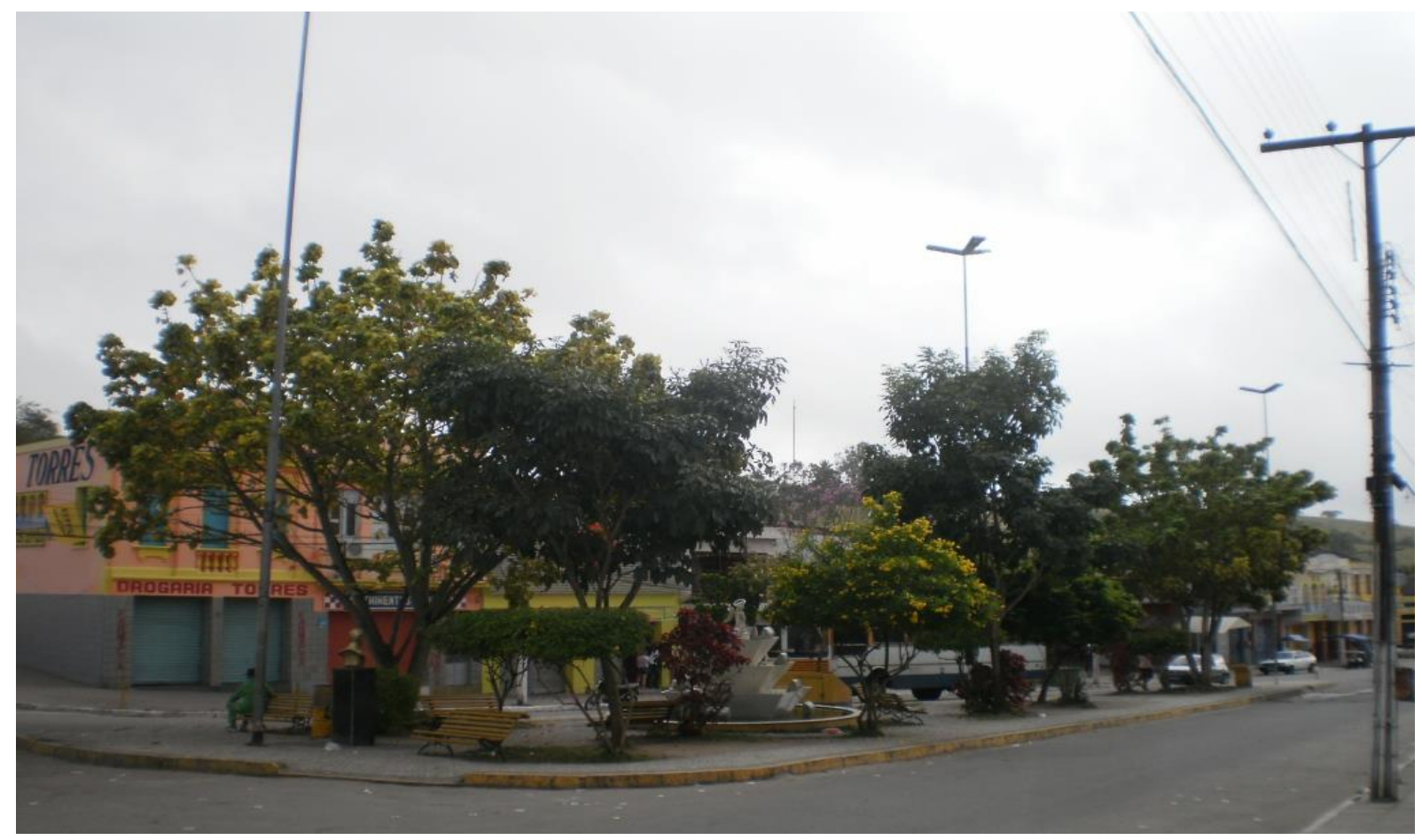

Figura 6

Imagem parcial da Praça Padre Josias Ferreira de Paula. Foto: Arquivo pessoal, 2013.

A partir do que foi acima refletido, a Praça Padre Josias Ferreira de Paula é considerada área verde por apresentar em sua composição elementos de vegetação 
arbórea nativa e artificial, além de em boa parte de sua área ser impermeabilizada. Segundo a classificação proposta por alguns autores que foi exposta no decorrer deste trabalho, conferiu-se ser a mesma determinada como Área Verde Pública e/ou de Uso Coletivo com espécies de composição mista. Enxergar como espaço livre a disposição de uso comum a todos as pessoas que quiserem lhe utilizar, ao ar livre sem nenhuma barreira ou cerca limitadora. E, também, como logradouro público cortado por vias públicas nas laterais.

\section{PRAÇA PADRE CALLOU DE ALENCAR}

Outra personagem bastante admirada pela população do município em estudo, é homenageado e eternizado pelo busto de sua fisionomia pessoal na história da cidade e memória das pessoas que o conheceram na época, bem como os mais jovens que não tiveram a oportunidade de estar com ele pessoalmente, conhecer a pessoa que esta recebendo, ate hoje, tal tributo.

Situada aproximadamente a 40 metros da primeira praça aqui falada, esta no centro da cidade, área de comércio, na Rua Eugênio Tavares de Miranda, região de grande valorização espacial pelos produtos e serviços que estão disponíveis. Foi reconstituída para exercer uma nova função no seio da sociedade, sendo sua finalidade principal ser uma praça de eventos, que podem acolher qualquer tipo de manifestação sócio e cultural (Figura 7). 


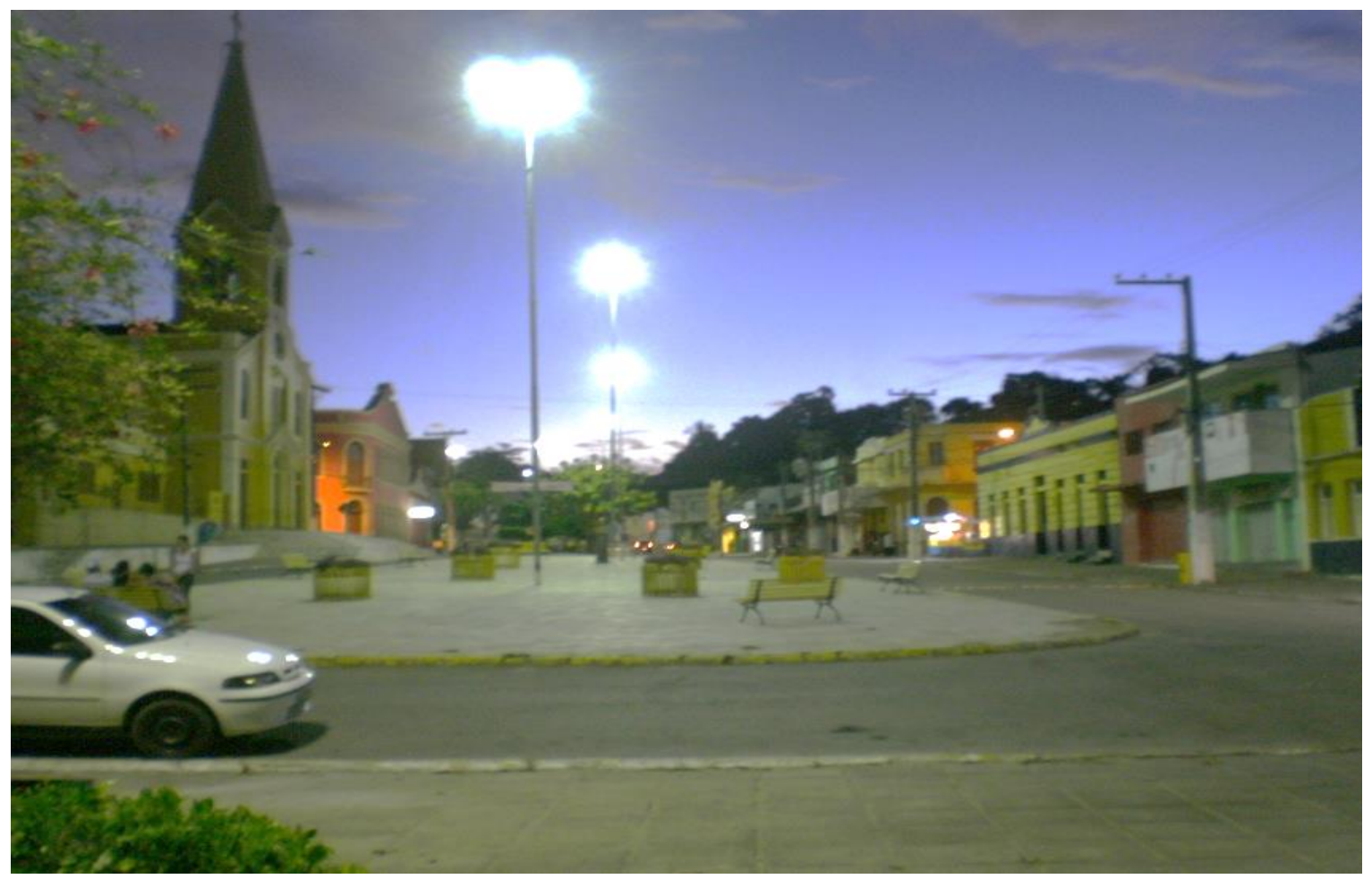

Figura 7

Imagem parcial da Praça Padre Callou de Alencar

Para tanto, ela se configura num exemplo de "Áreas livres não arborizadas" ou vazios urbanos, nos quais não ha presença de nenhum tipo de vegetação plantada, ou em vasos, nas áreas que abrange seu espaço. Assim, não influencia de forma positiva para o ambiente devido, principalmente, pela ausência de árvores que poderiam ser significativas em suas funções benéficas.

Sendo assim, os elementos bióticos e abióticos em suas relações diversas e, também, a localização das áreas verdes rurais ou urbanas vão condicionar as mais variadas definições ou enquadramentos na literatura. E, no caso das praças, enquanto parte do sistema urbano fica bem evidente a necessidade de um melhor mecanismo teórico / pratico, mesmo de forma sistêmica, que sirva para equacionar problemas de planejamento urbano, os quais irão rebater com certeza na sociedade que se beneficia desses espaços e / ou equipamentos urbanos. Os responsáveis por todo planejamento e preservação desse subsistema fica a cargo de gestores municipais e do bom senso dos frequentadores. 


\section{CONCLUSÃO}

O estudo do verde, em destaque o arbóreo, presente nas praças se compreendido numa lógica dinâmica em que todos os elementos ali presentes estão relacionados num processo de interdependência, pode-se perceber as funções que são naturalmente desempenhadas sem ser visto a olho nu mas, diante dos processos metabólicos e poéticos das arvores, toma-se conhecimento de sua atuação.

As constantes categorias que são utilizadas no senso comum com o proposito de definir que toda vegetação inserida nas áreas urbanas sejam áreas verdes, estão postas sem nenhum tipo de critério para tal. Assim, procurou-se realizar uma classificação de alguns espaços do município citado, mediante evidencias observadas em duas praças principais que exibem tipos distintos de áreas livres, uma delas apresentando elementos verdes e outra, totalmente desprovidas desses elementos.

\section{REFERÊNCIAS}

AMADOR, Maria Betânia Moreira. Sistemismo e sustentabilidade: questão interdisciplinar. São Paulo: Scortecci, 2011.

BENINI, Sandra Medina; MARTIN, Encarnita Salas. Decifrando as Áreas Verdes Públicas. Revista Formação, n.17, volume 2 - p. 63-80. Disponível em http://revista.fct.unesp.br/index.php/formacao/article/viewFile/455/489. Acesso em 30 mar. 3013.

BERTRAND, George. Paisagem e Geografia Física Global. Esboço Metodológico. Disponível em:

<http://xa.yimg.co/kq/groups/1624466/1240532828/name/paisagem+bertrand.pdf.> Acesso em 02 set. 2013.

GOMES, Maria Rosângela. Praças Públicas: Espaços de Contradições Intra urbanos: Reflexões a partir de Alguns Estudos de Casos. Anais do III SPGEO, Natal-RN, 26 a 29 de setembro de 2012.

HENRIQUE, Wendel. O direito à natureza na cidade. Salvador : EDUFBA, 2009.

LODOBA, Carlos Roberto; ANGELIS, Bruno Luiz Domingos. Áreas Verdes Públicas 
Urbanas: conceitos, usos e funções. Revista Ambiência. Guarapuava, PR. v.1 n.1 p. 125-139 jan./jun. 2005. ISSN $1808-0251$.

SANTOS, Antônio Silveira Ribeiro. Arborização urbana: considerações. 2002. Disponível em:<www.aultimaarcadenoe.com.br>. Acesso: 22 Mar. 2012.

SERPA, Angelo. O espaço público na cidade contemporânea. São Paulo: Contexto, 2009.

Agenda 21 Global. Disponível em: <http://www.mma.gov.br/responsabilidadesocioambiental/agenda-21/agenda-21-global>. Acesso: 25 Mar. 2013. 